\title{
Information modeling for quality management of a construction company in the context of economic digitalization
}

\author{
Alexandra Nalimova and Marina Alyeva* \\ Don State Technical University, 344000, Rostov-on-Don, Russia
}

\begin{abstract}
The article is devoted to the study of the features of quality control of the organization of construction processes based on the use of information technologies. The construction period is key to ensuring the design characteristics of capital construction projects. It is this stage of the life cycle that characterizes the adequacy of the organizational and managerial decisions made (the organizational and technological sequence of construction) and determines the actual quality indicators (functional efficiency and operational reliability) of the completed construction objects. Statistics of studies of cases that led to the manifestation of deviations from the established (design) quality indicators show that a decrease in the quality of construction products (including an increase in the duration of construction production) is almost never the result of any one, but occurs as a result of the interaction of several different negative factors (groups of negative factors). A special emphasis is placed on the technology of automated computer modeling (BIM technology), which accompanies all stages and stages of construction. It is noted that automated management can be either short-term, designed for the current year, or in the form of a long cycle.
\end{abstract}

\section{Introduction}

In the planning, design, construction, maintenance and renovation of erected structures, different and sometimes quite contradictory requirements are imposed on the construction materials used. The satisfaction of these requirements depends on their composition and manufacturing technology as well as on their resistance to short-term or long-term impacts of the environment. The art of a civil engineer is to combine the requirements imposed on structures with the capabilities of certain building materials at minimal monetary costs for the construction of the object and to obtain the decent quality of the final construction products [1].

The present digital economy is a new background for the development of the economy and business system. The introduction of digital information technologies gives way to a new treatment of the issue of quality management in a construction organization in terms of not only applied building materials but also of those being developed [2-3].

*Corresponding author: land12345@mail.ru 


\section{Materials and methods}

There were times when structures being constructed were relatively simple, and the number and possibilities of existing building materials were limited, it was relatively easy for an engineer to make a choice and pick out one or the other option. At that time, intuition and experience were the only factors that guided the engineer in making the final decision [2-4].

Nowadays, the complexity of structures being erected and the variety of building materials force the engineer to resort to applying science to solve various problems. In addition, to succeed in this regard, a civil engineer must be well aware of the basic principles that determine the behavior of building materials. This is the only opportunity for a civil engineer to be aware of the constant changes in the technology of building materials that is progressing at an ever-increasing pace. The use of integrated information technologies can assist an engineer in understanding and successfully handling the data on the nomenclature, parameters of building materials, and opportunities of building production [4-6].

The implementation of the construction management systems at every stage of structural design and project management involves the creation of a single expert database of the region and the whole industry on building materials and their production. This saves the engineer from long-time searching for the right readymade or semi-finished product. This reduces design time and increases the transparency of the design and organizational decisions being made.

As an example of solving complicated problems relating to building materials that a modern civil engineer has to challenge, let us consider the use of prefabricated structures of today's buildings. The key characteristics of such structures include appropriate mechanical, heat and sound insulation properties, meeting the requirements of aesthetics, as well as the resistance of the structure to environmental effects during the design life[7-10]. There exists a relationship among all these characteristics, as well as between each of them and the options available to the engineer at various stages of design, calculation, construction, operation and renovation. In the prepared database of the object information model, they can be presented as an option:

a) the size of the spans at the design stage;

b) making design decisions regarding distribution of the load transmitted to the structure;

c) implementation of the expert and automated quality control during the construction period;

d) control of the actual environmental conditions during the operation of the facility;

e) carrying out appropriate preventive and routine repairs.

Moreover, the quality control of the characteristics of building materials takes into account their mechanical properties through factors such as the type and composition of the material, the type of product and manufacturing technology, as well as the reaction of the material to the environment during the duration of service as it was originally designed[11$13]$.

\section{Results}

At various stages of development, selection, and usage of building materials, one is bound to turn to a variety of branches of knowledge which can be substantially simplified by unifying databases in a single software and information complex. The manufacturer with little understanding of the general requirements for a completed construction project 
develops and sells a limited spectrum of materials. After performing only a few limited laboratory and field testing, the manufacturer provides a consumer with some data on the characteristics of the materials they manufacture. Some of these characteristics, e.g. the modulus of elasticity and their strength, are quantitative, while others, such as corrosion resistance, are only qualitative.

The materials produced differ in both economic and qualitative parameters, and the manufacturer mostly concentrates on most marketable products. Facing with a number of existing materials that differ in cost, quality and characteristics, the design engineer must select the material that is most appropriate and economically advantageous for the structure under construction [14]. For optimal solutions, the design engineer is only guided by their intuition and experience, for they do not have such tools as advanced methodology and lor analytical tools they can rely on. Often, the engineer selects a material suitable for certain purposes based on several quantitative characteristics and then checks the qualitative compliance of the material with its other characteristics. The use of the information model will significantly simplify the choice of materials and provide enough functional transparency of the decisions made.

Except for exceptionally huge construction projects, a relatively small amount of materials required for a particular project does not justify the development of materials with new characteristics [15]. Therefore, the design engineer usually has to make a choice from the materials already produced. The design engineer can make a choice of the material necessary for the implementation of their project, guided by construction regulations or architectural and aesthetic considerations. This may simplify the selection process, but the decision may not always turn out optimal.

To make sure the structure under construction will carry out every assigned function, the designer can use one or both types of the valid technical conditions: detailed technical conditions for the production of works or technical conditions for operational characteristics. When using the first type of technical conditions, the engineer assumes that if the material is made in accordance with these conditions, it will have the desired performance characteristics. When using the second type of conditions, the engineer determines the required final performance and assigns responsibility for their achievement to the contractor [13-15].

In order to fully assess the advantages of the proposed method of assessing the quality of installation using BIM modeling, it is necessary to dwell a little more on the example of a structural solution of the coating in one of the shopping complexes of the city of Avsaya. The ground on the construction site is sandy silt, extending evenly to the marl, lying at a depth of about $13.5 \mathrm{~m}$ below ground level. The water table is approximately $6 \mathrm{~m}$ below the existing ground level. Given these circumstances, it was decided to apply a pile foundation. The possibility of a slight uneven precipitation of pile foundations that accept heavy concentrated loads was assumed, so the construction of the building cover had to be designed so that the precipitation of the foundations did not lead to undesirable consequences.

The steel structures of the truss supports are enclosed in towers made of monolithic reinforced concrete. It seemed logical to place stairs and elevators in these eight towers for the ascent and descent of visitors. It was also logical to use cross-box trusses.

Each of the four pairs of trusses is a double truss forming a box structure. These boxshaped cross trusses form a structural system that works in two directions. The height of the box truss is $3.97 \mathrm{~m}$, the width is $4.1 \mathrm{~m}$. The spans between the centers of the supports are equal. Before the construction of the object, a 3D model was built with reference to each mounting node. During the construction of the building, the control of the assembly units was evaluated with the data of the BIM model according to the quality parameters and the expected behavior of the structures. 


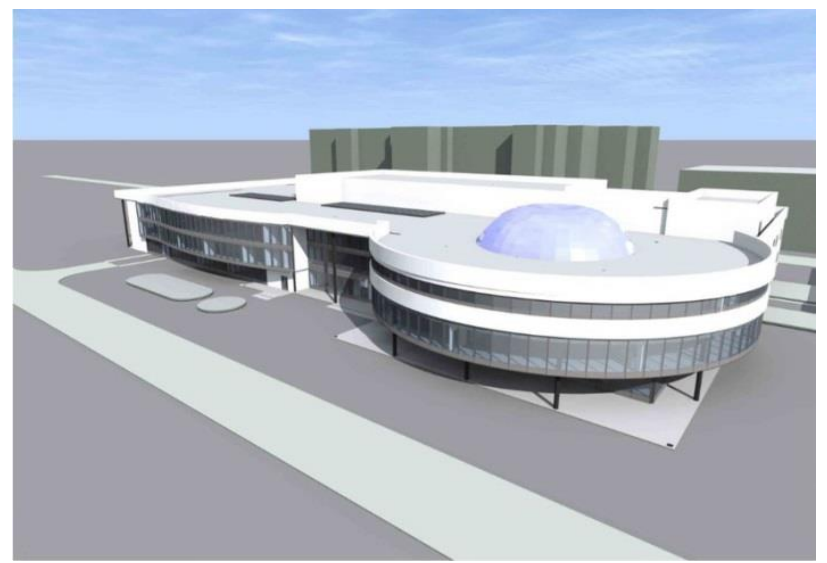

Fig. 1. Sketch of the shopping center building.Source:https://vmasshtabe.ru/wpcontent/uploads/2016/06/408550-vms-dhwnuTsdxlg.jpg

Parametric calculations of quality indicators are presented in Figure 2

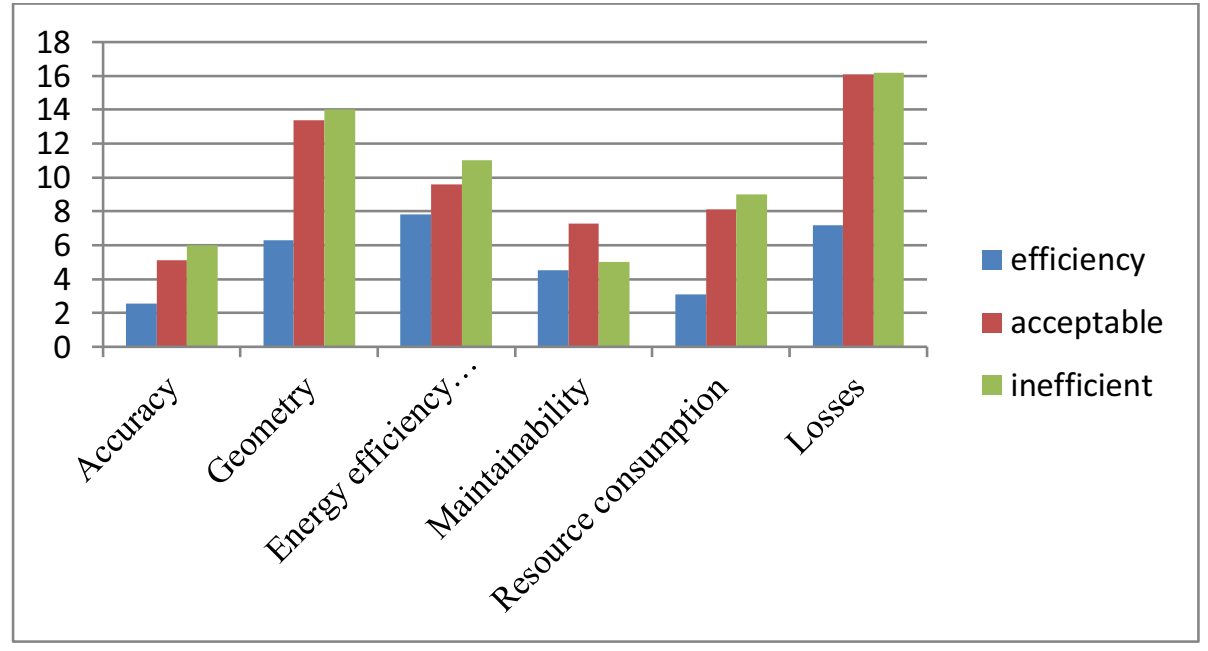

Fig. 2. Model of the effectiveness of quality control of an object (example of a shopping center). Developed by the author

\section{Discussion}

The technical conditions for the production of works allow the engineer to control the key (critical) stages of the construction process in great detail, but the contractor is normally placed in such a strict framework that any change to the project may be undesirable. However, in the case of technical conditions of performance specifications, additional benefits can be obtained through the ingenuity of the contractor, as well as guarantees that the desired performance will be achieved after a certain time. In the building industry, it is becoming increasingly popular to solve the problem, in which the conditions for the production of work are partially used and, at the same time, quality control is also 
performed which increases the chances of achieving the desired performance characteristics.

The impediments encountered in the construction industry are numerous and complex. Although there are many factors contributing to their emergence and growth, the most important drawback is the lack of sufficiently coordinated development of technology of the production of building materials.

Sometime ago, the principal funds were mainly invested in the development of military and space industries. The results were impressive. Thanks to this development, significant progress was made not only in creating the required technology in the industries, but it also significantly impacted the growth and development of technologies in other industries. Informatization facilitates the development and implementation of complex systems to operation in a relatively short period; to succeed at that, it was necessary to create advanced information and methodological systems. Such a systematic approach included defining the goal (i.e. problem statement), consideration of every option, selection of the obviously optimal option, implementation of the solution and evaluation of the results. In the construction industry, which is extremely multi-faceted and complex, such an approach could be used for making the best decision. Some of the data obtained from solving problems in the space industry can be easily used in the construction one.

The construction industry has two different opinions about methodological systems: a systematic approach to problem solving and building systems. The term "system" approach comes from the classical meaning of this word stating the use of new methods of system analysis in solve problems, simulation, and during operation.

The objectives are set with respect to desired performance characteristics rather than with respect to a particular technology or pre-existing models. The links within the system under study are highlighted in order to determine the impact of any options and decisions on other relevant decisions. Alternative solutions are tested on models. In turn, the term "building system" refers to the use of norms, labor, and energy to obtain any desired result.

The characteristics of the combination of all components in the project under construction are determined and then special subcontractors, who can produce individual components or sub-components in accordance with the technical specifications, are contracted. A special technical and legal team coordinates the purchase of reliable subsystems, checks their compatibility, and creates a sufficiently large building fund to attract contractors at a competitive price. As an example of the use of "building systems", we can take the development of structural systems for school buildings and the project of student dormitories at the University of California, carried out in accordance with a newly made structural system.

The definition of the purpose of the project under construction includes the establishment of operational criteria that consider the consumers preferences. To develop some possible ways to achieve these targets, it is vital that they are firstly expressed quantitatively, taking into account the following factors:

* Functionality as a measure based on the assessment of the consumer (how well the structure being constructed performs all the functions assigned).

* Reliability, i.e. the probability that the functionality of the project under construction will not be below the acceptable level during the originally assigned design life of the structure.

* The ability to restore is characterized by the measures required to maintain the functionality at least not below the acceptable level, as well as to restore the previous level of functionality in the event that such a decrease occurs. 
By expressing these characteristics in a functional form, the designer can establish optimal ratios and use analytical tools to evaluate alternative solutions.

With respect to building materials, operational suitability should be determined by taking into account the properties of the material that meet the needs of the constructed structure. For example, for structural concrete, mechanical, thermal and shrinkage properties should be included in the quantitative description of the term "worthiness".

«Reliability» of materials is determined based on the probability that the final product would meet the requirements of desired worthiness, as well as the ability to correctly predict changes in worthiness over time. These "probabilities" are effected by the degree of quality control implemented as well as the stock ratios adopted at the design stage.

Since structures that have no maintenance at all are rarely economically or technically feasible, certain repair costs are normally required.

Therefore, the term "recoverability» includes the estimation of the optimal ratio between the original cost and the cost of repair. In addition, probabilistic models should be used to establish the optimal balance between preventive maintenance and the need for routine one.

In today's PLAZA software packages, there have been developed and implemented some detailed analytical models to establish the relationship between such concepts as 'functionality", "reliability" and "recoverability". A start has already been made with the application of such ideas in the construction industry. An example of the use of such ideas in construction is the growing interest in the quality control of facilities being constructed.

\section{Conclusion}

The combined use of system analysis and materiology allows the engineer to implement the right approach to solving problems which can lead to the creation of more efficient and advanced engineering structures.

The method of the informational integrated analysis of systems has been effectively applied for some time in relation to certain construction processes. Materiology has contributed to a more complete study of existing building materials and the control of their properties.

This has led to a few valuable innovations in the field of building materials, project management, and the creation of unified information and expert systems being integrated into design activities.

Thus, with the complexity of contemporary facilities and the variety of existing building materials, the only way for the engineer to link the needs of construction with the available opportunities at a minimal cost is to combine the method of systems analysis and materiology.

\section{References}

1. J. Čamaj, J. Mašek, M. Kendra, Procedia Engineering 134, 224-230 (2016). DOI: 10.1016/j.proeng.2016.01.063

2. M. Hlatka, R. Kampf, G. Fedorko, Jour. Techn. Educ. Manag. Inform. 9(3), 889-898 (2020). DOI: 10.18421/TEM93.

3. M. Zoldy, Int. J. Automot. Technol. 20, 971-978 (2019). doi:10.1007/s12239-0190091-y. 
4. A. Beskopylny, A. Chukarin, B. Meskhi, A. Isaev, Transportation Research Procedia. IX International Scientific Siberian Transport Forum - Trans Siberia 2020. 39-46 (2021). DOI:10.1016/j.trpro.2021.02.045

5. A. Beskopylny, B. Meskhi, A. Veremeenko, A. Isaev, E. Kadomtseva, Transportation Research Procedia. IX International Scientific Siberian Transport Forum - TransSiberia 2020. 84-91 (2021). DOI:10.1016/j.trpro.2021.02.050

6. B.Ch. Meskhi, V.N. Azarov, A.I. Evtushenko, Ju.V. Startseva, IOP Conference Series: Materials Science and Engineering. 012058 (2020) DOI:10.1088/1757899X/1001/1/012058

7. M. Poliak, Ener. sour. 7, 25-29 (2019). DOI: 10.1080/15567036.2020.1776796

8. R. Rajkovic, N. Zrnic, S. Bojic, Transport. In: Commer. Transp., 159-173. (2016). doi: 10.1007/978-3-319-21266-1_10.

9. T.B. Mikheeva, E.V. Murugova, SHS Web of Conf (2019). doi.org/10.1051/shsconf/20197007003

10. S.V. Pervukhina, O.A. Evtouchenko, L.Iu. Kotliarenko, M.P. Churikov, SHS Web of Conferences (2020). Curr. Iss. Mod. Ling. Hum., 232-244, doi: $10.1051 /$ shsconf $/ 20208801013$

11. M.A. Tamarkin, A.N. Isaev, E.V. Murugova, V.I. Butenko, MATEC Web of Conf (2018). doi:10.1051/matecconf $/ 201822601025$

12. S. Pervukhina, V. Demchenko, E3S Web of Conf. (ITSE 2020). 18033, doi:10.1051/e3sconf/202021018033

13. N.B. Boeva-Omelechko, M.R. Zheltukhina, O.P. Ryabko, G.G. Matveeva, E.V. Murugova, I.A. Zyubina, Space and Culture, India. 4, 112-121 (2018). doi: 10.20896/saci.v6i4.387

14. J.A. Bickford, M.P. Lewis, G.F. Simons, Multiling. Multicult. Dev., 36 (5) 513-527 (2014). doi: 10.1080/01434632.2014.966827 